\title{
CONFRONTING MEASLES OUTBREAK: PUBLIC HEALTH INTERVENTION POLICIES IN CRETE
}

E. Dardamani ${ }^{1}$, E. Loubounis ${ }^{2}$, P. Koutrakou ${ }^{3}$, M. Zacharioudaki ${ }^{1}$, M. Lioudaki ${ }^{1}$, E. Galanakis ${ }^{1}$ ${ }^{1}$ Heraklion University Hospital of Crete, Department of Paediatrics, Heraklion, Greece.

2 Directorate of Public Health, Region of Crete, Heraklion, Greece.

${ }^{3}$ Heraklion University Hospital of Crete, Department of Vaccines, Heraklion, Greece.

\section{Background}

Measles has re-emerged in several European countries, including Greece. This outbreak has created a need for vigilance, epidemiological observation and enforcement of vaccination.

The aim of this study is to describe the policies applied in Crete in order to confront this re-emergence of measles.

\section{$\underline{\text { Methods }}$}

In collaboration with the regional state health and education authorities, we checked immunization records of all children attending primary school. Families of children with missing doses were called by telephone and advised on the importance of and the practicalities of fulfilling the vaccination schedule.

A hotline for healthcare professionals was launched, aiming both to timely record new cases and to provide consultation on diagnosis and management issues.

\section{$\underline{\text { Results }}$}

Starting from November 2016, 27,025 vaccination records have been checked from children attending all primary schools in Crete.

Table 1: Prevalence of unvaccinated and clinical cases in Crete

\begin{tabular}{|l|c|}
\hline Target Population & 43,392 \\
\hline Records checked & $27,025(62.3 \%)$ \\
\hline Two doses & $25,098(94.0 \%)$ \\
\hline One dose & $1,476(5.53 \%)$ \\
\hline No doses & $103(0.39 \%)$ \\
\hline$<2$ doses & $1,579(5.92 \%)$ \\
\hline Called for advice & 1369 \\
\hline Measles cases & 29 \\
\hline Pediatric cases & 17 \\
\hline Expected cases & 158 \\
\hline
\end{tabular}

Two doses of measles vaccine were documented in $25,098(94 \%)$, one dose in $1,476(5.53 \%)$ and no doses in only 103 $(0.39 \%)$ children.

A total of 1,369 families were advised on the missing doses. Medical contraindication was confirmed in 18 cases and vaccine hesitancy in 4. In 11 cases, parents asked for more information by an Infectious Disease expert (Table 1).

Up to the beginning of May 2018, only 29 measles cases (none fatal) were recorded in Crete (instead of 158 expected), as compared to 2,747 (including 3 deaths) in Greece as a total (Fig.1).
All measles cases occurred in poorly immunized children and adults $(<2$ doses).

The intervention is still active targeting to cover the whole child population of 43,392 children.

\section{Conclusions}

Following an intervention with hotline and telephone reminders, measles prevalence in the study area was minimal, suggesting that intensive prevention policies may work well in vaccinepreventable diseases.

Fig.1: Vaccination coverage and clinical cases of measles in Crete

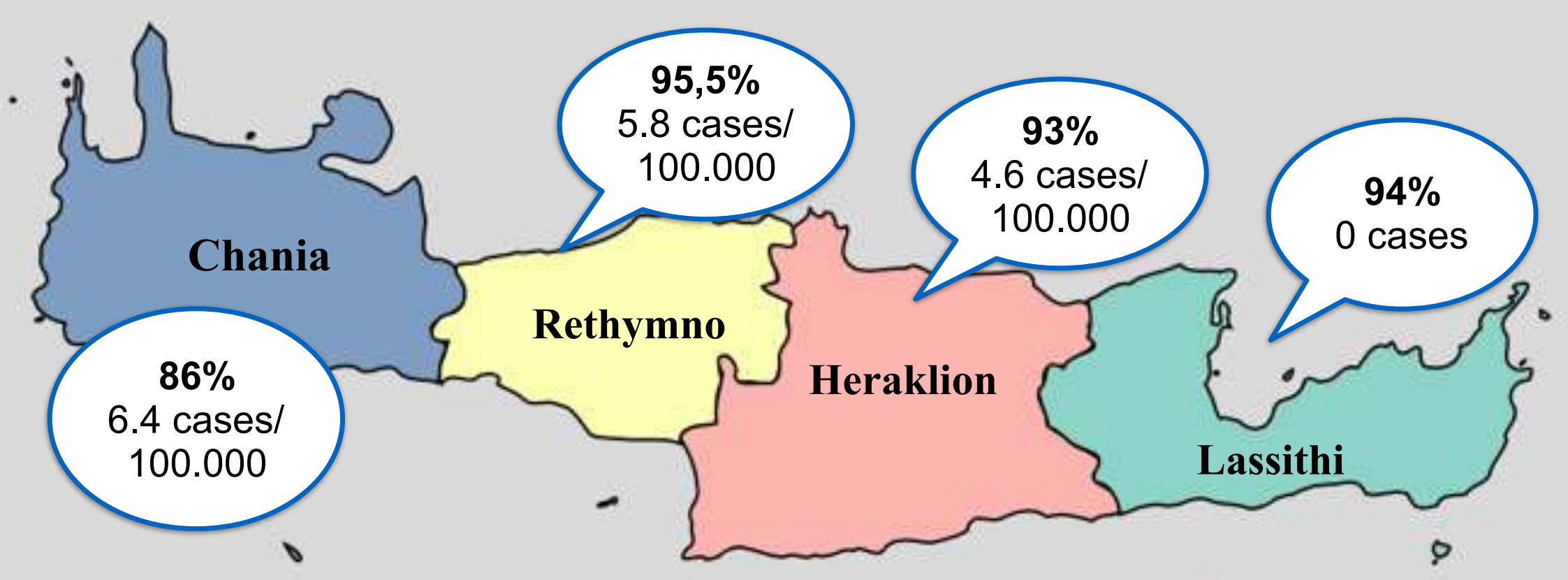

\section{References}

1. Klinkenberg, D., Hahné, S. J., Woudenberg, T., \& Wallinga, J. (2018). The reduction of measles transmission during school vacations. Epidemiology (Cambridge, Mass.).

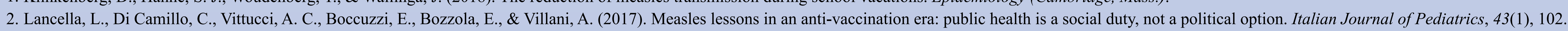

3. Weekly update on the number of measles notified cases in Greece, KEELPNO 